\title{
Vitamin D Combination of Osseous and Non-Osseous Benefits with Supplementation
}

\author{
Makgabo John Tladi FCS, MMED ${ }^{1 *}$ and Mamokoma Becky Kgole, BSC, MBChB, FCP, MMED ${ }^{2}$ \\ ${ }^{1}$ Louis Pasture Private Hospital, Pretoria, South Africa \\ ${ }^{2}$ Cert in Pulmonology, Sefako Makgatho Health Science University, Dr George Mukhari Academic Hospital, Medforum Private \\ Hospital, Pretoria, South Africa
}

*Corresponding author: Makgabo John Tladi FCS, MMED, Louis Pasture Private Hospital, South Africa

ARTICLE INFO
Received: 幽 September 24, 2020
Published: 㓞 October 02, 2020

Citation: Tladi MJ , Kgole MB. Vitamin D Combination of Osseous and Non-Osseous Benefits with Supplementation. Biomed J Sci \& Tech Res 30(5)-2020. BJSTR. MS.ID.005021.

Abbreviations: AJs: Adherens Junctions; WHO: World Health Organization; RCT: Randomised Controlled Trials; COVID: Coronavirus Disease; ACE: Angiotensin-Converting Enzyme; PTH: Parathyroid Hormone; COPD: Chronic Obstructive Pulmonary Diseases; CRPS: Complex Regional Pain Syndrome; TB: Pulmonary Tuberculosis

\begin{abstract}
A living tissue needs nutrients to survive and bone physiology should be balanced in order to be healthy. Vitamin D plays a critical role for both bones and other body tissue homeostasis. Various conditions have been found to be associated with low vitamin $\mathrm{D}$ and low levels of vitamin $\mathrm{D}$ in the bone can manifest from childhood. Other medical conditions (extra osseous) have also been found to be associated with low vitamin D. Currently the world is under attack from the Covid-19 pandemic, but reports indicate that we would benefit if the levels of vitamin D are optimum. Vitamin D enhances both the innate and cellular immunities that are crucial in fighting against the microorganisms that cause various infections. Studies report the prevention of respiratory tract infections if the levels of vitamin D in the body are optimal. Mechanisms of prevention include lower viral replication and reduction of an inflammatory process in the lungs. Various medical conditions can affect the bone directly or indirectly. Some literature studies have shown that there could be an association between low vitamin D and medical conditions, including orthopaedic conditions. Other secondary bone diseases can be prevented if the level of vitamin $\mathrm{D}$ is within normal range. We believe that giving patients vitamin $\mathrm{D}$ can reduce the cost of operations as well increase patients' lifespan. The aim of this review article is to outline the benefits of vitamin $\mathrm{D}$ for both osseous and non-osseous conditions and also to convey the importance of knowledge of vitamin D supplementation for an orthopaedic surgeon.
\end{abstract}

Keywords: Vitamin D; Covid-19; Corona virus; Fracture; Orthopaedic; Homeostasis; Mechanisms; Osteoporosis; Supplementation; Retrospective Studies

\section{Introduction}

Vitamin D is a micronutrient that is also a pro-hormone for the active hormone calcitriol. It is mostly produced by skin upon exposure to adequate sunlight. In addition, a small amount is ingested from supplementation or from foods, e.g. fatty fish, beef liver, egg yolk and cheese. Some foods, including breakfast cereal, are fortified with vitamin $\mathrm{D}$ to increase its availability $[1,2]$. Optimal serum vitamin D levels have been shown to have health benefits that expand beyond prevention osteoporosis, prevention of falls in the elderly, reduced incidence of colorectal cancer, improved insulin response, improved symptoms of depression, and better tooth attachment [3]. It is important in the regulation of a large number of genes, including those responsible for cell proliferation, cell differentiation and programmed cell death (apoptosis). It is also reported to play a role in the homeostasis of the immune system and prevention of the development of autoimmune diseases [1]. Vitamin D helps tissues to maintain tight junctions, gap junctions, and adherens junctions (AJs) that can be disturbed by viruses and other microorganisms [4,5]. Low levels of vitamin $\mathrm{D}$ have been associated with infection from different types of microorganisms, as well as in metabolic disorders.

Vitamin D can potentially be protective against respiratory tract infections [6]. The winter months have been associated with increased transmission of respiratory viruses, including the SARS CoV-2. This has been attributed in part to lower levels 
of vitamin D, primarily due to decreased exposure to the sun [7]. The world is currently experiencing a surge of the coronavirus disease that began late in 2019 in Wuhan, China and was declared a pandemic by the World Health Organization (WHO) in March 2020 [8]. Millions of lives have been lost and the global economy continues to experience unmitigated distress. Although clinical evidence to support reduction in mortality through randomised controlled trials (RCT) is inadequate, there have been reports of an association between the level of vitamin D serum with the severity and rate of mortality in retrospective studies on the coronavirus disease (COVID-19) caused by SARS-CoV-2 [9,10]. The epithelial cells of the blood vessels, intestines, lungs, kidneys and heart have a high number of angiotensin-converting enzyme 2 (ACE2). The coronavirus binds to the ACE 2 receptors, and thus organs that have these receptors can be affected by the virus [11]. Han et al. report that ventilated patients who are given a higher dosage have a short length of hospitalization [12]. In a study by Biegalski, 98.9\% of those who have lost their lives due to Covid-19 had vitamin D levels below $20 \mathrm{ng} / \mathrm{ml}$ [7].

In children, intake of vitamin D has proven to reduce the risk of developing type 1 diabetes [13]. Glycaemic control has been achieved following supplementation in both type 1 and type 2 diabetes $[14,15]$. However, not all researchers support the benefits of vitamin D in diabetes. Haroon et al. reported no improvement of hyperglycaemia, beta cells secretion nor insulin sensitivity following vitamin D supplementation [16]. Orthopaedic surgeons regularly manage the complications arising from poorly controlled diabetes, as well as bone conditions of patients with diabetes. Having adequate glycaemic control would most likely result in a reduction of the high costs that are associated with diabetic complications. There would be the prevention and delay of peripheral neuropathy and arthrosclerosis respectively, following supplementation in diabetes [17]. In addition, pain scores havebeen shown to improved following supplementation [18]. A high number of orthopaedic patients have presented with low levels of vitamin D. A study by Pal et al. found that about $91.3 \%$ of these patients were classified as having a vitamin D deficiency [19]. The United Kingdom recommends keeping levels of serum vitamin D above $30 \mathrm{nmol} / \mathrm{L}$ to prevent deficiency. A healthy diet with adequate levels of vitamin D, together with safe sunlight exposure, is recommended for the maintenance of adequate levels of vitamin D. In particular, these recommendations are important in view of the worldwide isolation rules to which populations must adhere in an attempt to reduce the impact of Covid-19 [1]. The aim of this review article is to outline the benefits of vitamin D for both osseous and non-osseous conditions and also to highlight the importance of a knowledge of vitamin D supplementation for an orthopaedic surgeon.

\section{Physiology of Vitamin D}

Vitamin D absorbed from both the gastrointestinal tract and the skin is hydroxylated within the liver into 25-hydroxyvitamin
D [25(OH)D]. The final product and the active form of vitamin D is produced in the kidneys where 25(OH)D is hydroxylated to $1,25(\mathrm{OH}) \mathrm{D}$, also known as calcitriol $[2,20]$. The enzyme that hydroxylates the $25(\mathrm{OH}) \mathrm{D}$, called 25-hydroxylase, is also found in antigen-presenting cells, macrophages and in other organs, e.g. the mammary glands, colon and prostate [2]. The major role of vitamin $\mathrm{D}$ is to regulate serum calcium levels and maintain its homeostasis through a feedback loop with the parathyroid hormone (PTH). This is essential for collagen matrix mineralization [2,21]. It is not unusual to find low levels in sunny areas [22,23]. These low levels are also found in university students [24]. Drugs which are associated with low vitamin D include, anti-epileptics, antibiotics, anti-inflammatory agents, antihypertensive drugs, antiretroviral drugs, endocrine drugs, and some herbal medicines [4]. Obesity, bone tumours, malabsorption syndromes, renal disease and smoking have also been associated with levels of low vitamin D $[21,25]$. Darker skin, sunscreen use and covering of the skin observed in adherents to some religions, cultures and customs can lead to reduced exposure to the sun and thereby reduce the availability of vitamin D from its major source $[1,2,7]$.

\section{Immunology and Microbiology}

Over 200 viruses have been implicated in the aetiology of upper respiratory infections. These infections have been reported to be worse in individuals with respiratory diseases, e.g. chronic obstructive pulmonary diseases (COPD) and those with low levels of vitamin D [1]. Various mechanisms of Vitamin D have been suggested to reduce the risk of virus infections. Vitamin D can assist in enhancing cellular innate immunity through the induction of antimicrobial peptides, which include human cathelicidin, LL-37, by 1,25-dihdroxyvitamin D and defensins [4,26,27]. Innate immunity and the production of antimicrobial peptides have been found to play a role in tissue protection against microorganisms (virus, bacteria and fungi), which cause infections [4,5,27]. Cathelicidin has direct antimicrobial activities while LL-37 can reduce influenza virus replication $[28,29]$. Human macrophages and monocytes rely on vitamin D/LL-37 axis to fight against mycobacteria and slow its growth $[6,30,31]$. A supplement of $400 \mathrm{IU} /$ day vitamin D was found to improve the innate immune response against dengue virus [32]. Vitamin D is also reported to enhance cellular immunity, which helps to reduce the cytokine storm induced by the innate immunity. Sharifi et al. found that vitamin D supplement resulted in decreasing the effects on serum TNF-a, IFN-c, and IL12p70 levels, as well as inhibiting Th1 immune responses. However, no effect was observed on the IL4 and IL10 or the Th2 responses [33].

The increment of plasma renin activity and higher angiotensin 2 , as well as higher renin-angiotensin-system (RAS) activity, can be due to low vitamin D [7]. It has been shown that in patients with Covid-19, the SARS-CoV-2 virus binds to ACE2 receptors, especially in the respiratory tract, which can be blocked by an inhibitor of the cellular serine protease [25,34]. Calcitriol in animal studies was 
found to have a protective role by alleviating lipopolysaccharide (LPS)-induced acute lung injury [35]. Vitamin D has been shown to assist with stimulation of surfactant synthesis. The corona virus has a high affinity with type II pneumocytes. The reduction of the pneumocytes leads to an increase in surface tension by decreasing the surfactant level in Covid-19 [25,36-38]. However, not all support the relationship of Covid-19 with vitamin D serum concentrations. Hastie et al. found that there was no relationship between low vitamin D and ethnicity after analysis of UK Biobank data [39].

\section{Orthopaedic conditions and vitamin D}

Conditions that are known to be associated with low vitamin D include rickets, osteoporosis, osteomalacia, stress fractures and tumours. Serum vitamin D levels are often part of the initial workup [40]. Michelson and Charlson reported that about $66,7 \%$ of patients presenting for elective foot and ankle procedures had low vitamin D levels [41].

\section{Falls and Fractures}

Marcelli et al. reported that vitamin D has a role in reducing the risk of falling, hence preventing the incidence of low-energy (fragility) fractures [42]. Low levels can be seen in elderly patients who sustain hip fractures [43]. About $30 \%$ of elderly patients lose their lives 12 months after sustaining a low-energy hip fracture [44]. By contrast, some studies have not shown that the supplementation of vitamin D can prevent a fractures. Kahwati et al. found that the combination of vitamin D with calcium, or given alone, was not associated with a reduction of fractures in the elderly, the combination was associated with increased incidence of kidney stones [45]. Vitamin D plays a role in fracture healing and thus adequate levels are linked to reduced morbidity [46].

\section{Diabetes and Bones}

There has been an association of vitamin $\mathrm{D}$ with pathogenesis of both type 1 and type 2 diabetes mellitus. The suggested mechanism includes the regulation of plasma calcium that also regulates insulin production [47]. Vitamin D receptors have been detected in the beta cells of the pancreas that are destroyed in type 1 diabetes and these receptors have also been found in adipose tissue and other cells that are influenced by insulin; hence they have been implicated in insulin resistance [48]. Patients with low levels can have high glycosylated hemoglobin (HbA1c) [49]. The orthopaedic complications of diabetes include diabetic foot, Charcot, adhesive capsulitis, osteoporosis, diffuse idiopathic skeletal hyperostosis, delay in bone healing, tendinopathy, and periprosthetic infections , while the management of these complications is associated with high costs [50,51]. Having a normal blood glucose level would result in a reduction of the morbidity associated with the complications of diabetes. Post-operative sepsis can be associated with poor diabetic control, while tight serum glucose control usually has less incidence of sepsis.

\section{Pain and Musculoskeletal Conditions}

Vitamin D is involved in various mechanisms that can lead to pain. Supplementation of vitamin D has been shown to improve the pain score, whereas low levels of vitamin D have been associated with subacromial impingement syndrome [18]. Nonspecific musculoskeletal pain is often difficult to manage. Plotnikoff and Quigley reported an association of nonspecific musculoskeletal pain with low levels of vitamin D. The low levels were also found in patients that are normally considered low risk [52]. The reason for pain reduction is because of the ability of vitamin $\mathrm{D}$ to decrease inflammatory mechanisms.

\section{Osteoarthrosis}

Vitamin D has been associated with the development of osteoarthritis because of changes in the subchondral bone [53]. Gharaibeh et al. reported that $100 \%$ of patients with big-joint osteoarthritis had low levels of vitamin D [54]. By contrast, Cakar et al. fractures association of osteoarthritis knee pain with levels of vitamin D [55]. Inflammatory bowel disease (Crohn's disease and ulcerative colitis) extraintestinal manifestations include developed osteoarthritis that may need to be managed with arthroplasty. The other complication of inflammatory bowel disease is the development of osteoporosis and avascular necrosis due to steroid treatment [56-58]. The benefits of vitamin D in inflammatory bowel diseases include reduced risk for operation, decrease in inflammatory markers, reduction in developing anaemia, decrease in the incidence of developing colo-rectal cancer and an increased response to biological treatment $[59,60]$. It is possible that the incidence of developingosteoarthritisin inflammatorybowel disease could be reduced if the disease is controlled by supplementation. However, there is some controversy regarding the use of vitamin D for rheumatoid arthritis. Some studies have found that there were better outcomes of the disease with supplementation, whilst others did not [61,62]. Rheumatoid patients can have low levels of vitamin D in winter which is a season that is associated with disease severity [63]. Some reports propose that supplementation has not been shown to prevent the development of rheumatoid arthritis [64]. The treatment of arthritis involves arthroplasty and for patients who select this one should also evaluate their vitamin D status, although the role is not clear [65].

\section{Tuberculosis}

Mycobacterium tuberculosis affects various organs, especially the respiratory system. Some studies report the association of pulmonary tuberculosis (TB) with low vitamin D, as well as benefit from UVB in the treatment of TB $[66,67]$. Brighenti et al. reported that there is an increased risk of infection with mycobacterium tuberculosis in people with a vitamin D deficiency, however, in 
the absence of a clear deficiency no significant benefit has been demonstrated with supplementation in the management of TB [31]. Supplementation can increase the proportion of sputum smear, and culture conversion that can help with the diagnosis of pulmonary TB [68]. Talat et al. reported that there is a five times higher risk for pulmonary TB to progress to clinical disease if a patient has low vitamin D [69]. Spinal tuberculosis is a common spine infection with an increased susceptibility in developing countries and has been demonstrated to be associated with low vitamin D status [12]. Children with various osteoarticular TB were found to have low vitamin D levels [70]. However, not all have found the benefits of supplementing tuberculosis patients $[31,71]$.

\section{Complex Regional Pain Syndrome}

Lee et al. reported the development of complex regional pain syndrome (CRPS) in post-menopausal women who had sustained distal radius fracture and were treated surgically. This was associated with vitamin D levels and the incidence varied in relation to the severity of the deficiency. Women whose vitamin D levels met the criteria for deficiency had a higher incidence of CRPS at $22 \%$ followed by $15 \%$ in those classified as insufficient, and as low as $8 \%$ when the levels were sufficient [72]. Generally, supplementation of vitamin $\mathrm{C}$ to high risk individuals has been shown to decrease the development of CRPS [73]. Hence more clinical trials are needed to ascertain whether vitamin D supplementation can play a critical role in the prevention of CRPS, a condition which is difficult to manage.

\section{Depression and Musculoskeletal}

In treating depression, the role of vitamin D requires further scientific evidence. Vitamin D deficiency has been found in patients with depression in various studies. Almost $100 \%$ of depressed women were found to have low levels in a study by Ameri [74]. Although some benefit was reported with supplementation, the evidence remains scanty [75-78]. Alavi et al. [77] found benefits of vitamin D supplements in patients who had depression while Fraington and Moller [75] did not. Mood was improved in type 2 diabetes after vitamin D supplementation [79]. Other studies have suggested the reason for low vitamin D levels is because depressed patients lack interest in life activities; they remain indoors and their exposure to the sun is reduced [80]. There is an association between depression and orthopaedics where depression can be found in both trauma and non-trauma cases $[81,82]$. About $61 \%$ of orthopaedic in-patients were found to have symptoms of depression [83]. Although the literature shows a discrepancy between vitamin D supplementation and depression, we recommend that serum levels should at least be optimized.

\section{Replenish Management}

Treatment should be commenced when the serum vitamin D level is below normal levels [7]. It appears that the appropriate regimen and dosage of vitamin $\mathrm{D}$ has not been well documented. Pepper et al. found that at least 36 regimens are used to replenish vitamin D [84]. Some have reported that small daily doses do well as compared to a high loading dose because they might be metabolized and used differently [85]. Tladi recommends usage of a regimen that contains higher vitamin $\mathrm{D}$ for replenishment therapy in patients with a deficiency, as well as an empiric dose for patients who present for orthopaedic surgery [86]. Serum levels of more than $60 \mathrm{ng}$ per millilitre $(150 \mathrm{nmol}$ per litre) have been associated with increased risk of pancreatic cancer, vascular calcification, and death from any cause, but more studies are needed [85]. There have been reports of contracting tuberculosis while using higher dosages. One should aim to have functional serum levels of vitamin $\mathrm{D}$; as a result, a treatment regime that is safe to use is recommended.

\section{Discussion}

It can be seen that one should prescribe vitamin $\mathrm{D}$ to orthopaedic patients because there are multiple benefits, both osseous and extra-osseous, and some that are life-saving. Although there is controversy regarding prevention of falls in the elderly, we believe that supplementation would be of benefit, especially in the case of deficiency. Elderly patients tend to have diabetes and cardiovascular diseases that may give rise to other complications requiring intervention by the orthopaedic surgeon. Optimization of vitamin D levels may assist in improving the healing of wounds and fractures, particularly in this population. There have been reports of improving patients with cardiovascular diseases. Blood pressure in hypertensive patients could be reduced following supplementation $[7,17]$. We believe that supplementation might help with managing co-morbidities, e.g. hypertension and diabetes, as well as improving mood, in addition to preventing falls. As the world continues to fight the Covid-19 pandemic the role of vitamin D remains controversial. We believe it is important to maintain normal serum levels of vitamin D and that there is no harm in presumptuous supplementation in the case of acute respiratory disease.

Ventilated patients may have a shorter stay in the intensive care unit (ICU), which not only creates space for others but also reduces mortality and morbidity following ICU discharge. Other infections may be prevented with supplementation, especially to optimal levels. The involvement of vitamin D with inflammation can result in fewer side effects that are normally associated with analgesia. Chronic use of non-steroidal anti-inflammatory drugs can cause renal failure that also predisposes the body to have low vitamin D. Most orthopaedic patients present to health care facilities due to pain. These patients may benefit if vitamin D is added to the analgesia. The US Endocrine Society does not recommend routine screening of non-risk individuals [21]. However, we feel that there are multiple benefits with supplementation in deficient patients and that this warrants further screening. It is uncertain which 
regime is ideal. One should use the regime that will make the serum vitamin D normal. Further clinical trials are needed to determine further extraosseous benefits of vitamin D and to guide appropriate screening and supplementation. We advocate public awareness of the high risk of low levels of vitamin D, as well as the multiple benefits that would accrue if the levels are optimal.

\section{Conflict of Interest Statement}

The authors declared that the manuscript was conducted in the absence of any commercial or financial relationship that could be construed as a potential conflict of interest.

\section{Funding}

The was no funding given for this manuscript

\section{References}

1. Lanham New SA, Webb AR, Cashman KD, Buttriss JL, Fallowfield JL, et al. (2020) Vitamin D and SARS-CoV-2 virus/COVID-19 disease. BMJ Nutr Prev Heal 3(1): 106-110.

2. Patton CM, Powell AP, Patel AA (2012) Vitamin D in orthopaedics. J Am Acad Orthop Surg 20(3): 123-9.

3. Vieth R (2011) Why the minimum desirable serum 25-hydroxyvitamin D level should be $75 \mathrm{nmol} / \mathrm{L}$ (30ng/ml). Best Pract Res Clin Endocrinol Metab 25(4): 681-691.

4. Grant WB, Lahore H, Mc Donnell SL, Baggerly CA, French CB, et al. (2020) Evidence that vitamin D supplementation could reduce risk of influenza and covid-19 infections and deaths. Nutrients 12(4): 988.

5. Schwalfenberg GK (2011) A review of the critical role of vitamin D in the functioning of the immune system and the clinical implications of vitamin D deficiency. Mol Nutr Food Res 55(1): 96-108.

6. Bergman P, Lindh AU, Bjorkhem Bergman L, Lindh JD (2013) Vitamin D and respiratory tract infections: A systematic review and meta-analysis of randomized controlled trials. PLoS One 8(6).

7. Biesalski HK (2020) Vitamin D deficiency and co-morbidities in Covid-19 patients: A fatal relationship? NFS J 20: 10-21.

8. Peeri NC, Shrestha N, Rahman MS, Zaki R, Tan Z, et al. (2020) The SARS, MERS and novel coronavirus (COVID-19) epidemics, the newest and biggest global health threats: What lessons have we learned? Int J Epidemiol 49(3): 717-726.

9. Ali N (2020) Role of vitamin D in preventing of Covid-19 infection, progression and severity. J Infect Public Health.

10. Zhang Y, Fang F, Tang J, Jia L, Feng Y, et al. (2019) Association between Vitamin D supplementation and mortality: Systematic review and metaanalysis. BMJ: 366.

11. Cao Z, Wu Y, Faucon E, Sabatier JM (2020) SARS-CoV-2 \& Covid-19: Keyroles of the "Renin-Angiotensin" System / Vitamin D Impacting drug and vaccine developments. Infect Disord Drug Targets 20(3): 348-349.

12. Han JE, Jones JL, Tangpricha V, Brown MA, Hao L, et al. (2016) High dose Vitamin D administration in ventilated intensive care unit patients: A pilot double blind randomized controlled trial. J Clin Transl Endocrinol 4: 59-65.

13. Hyppönen E, Läärä E, Reunanen A, Järvelin MR, Virtanen SM (2001) Intake of vitamin $\mathrm{D}$ and risk of type 1 diabetes: A birth-cohort study. Lancet 358(9292): 1500-1503.

14. Schwalfenberg G (2008) Case report improvement of glycemic control with vitamin D3 repletion. Can Fam Physician 54: 864-866.

15. Mohammadian S, Fatahi N, Zaeri H, Vakili MA (2015) Effect of vitamin
D3 supplement in glycemic control of pediatrics with type 1 diabetes mellitus and vitamin D deficiency. J Clin Diagnostic Res 9(3): SC05-SC07.

16. Nigil Haroon N, Anton A, John J, Mittal M Effect of vitamin D supplementation on glycemic control in patients with type 2 diabetes: A systematic review of interventional studies. J Diabetes Metab Disord14: 3.

17. Papandreou D, Hamid ZTN (2015) The role of vitamin D in diabetes and cardiovascular disease: An updated review of the literature. Dis Markers 2015: 580474.

18. Shipton EA, Shipton EE (2015) Vitamin D and pain: Vitamin D and its role in the aetiology and maintenance of chronic pain states and associated comorbidities. Pain Res Treat 2015: 904967.

19. Pal CP, Kumar H, Kumar D, Mittal V, Deshwar G, et al. (2016) Prevalence of vitamin D deficiency in orthopaedic patients: A single-centre study. J Clin Orthop Trauma 7(2): 143-146.

20. Teymoori Rad M, Shokri F, Salimi V, Marashi SM (2019) The interplay between vitamin D and viral infections. Rev Med Virol 29(2): 1-16.

21. Holick MF, Binkley NC, Bischoff Ferrari HA, Gordon CM, Hanley DA, et al. (2011) Evaluation, treatment, and prevention of vitamin D deficiency: An endocrine society clinical practice guideline. J Clin Endocrinol Metab 96(7): 1911-1930.

22. Mogire RM, Mutua A, Kimita W, Kamau A, Bejon PM, et al. (2020) Prevalence of vitamin D deficiency in Africa: A systematic review and meta-analysis. Lancet Glob Heal 8(1): e134-142.

23. Chutterpaul P, Paruk F, Cassim B (2019) Prevalence of vitamin D deficiency in older South Africans with and without hip fractures and the effects of age, body weight, ethnicity and functional status. J Endocrinol Metab Diabetes South Africa 24(1): 10-15.

24. Visser J, Knight K, Philips L, Visser W, Wallace M, et al. (2019) Determinants of serum 25-hydroxyvitamin D levels in healthy young adults living in the Western Cape, South Africa. South African Fam Pract 61(4): 150-158.

25. Ebadi M, Montano Loza AJ (2020) Perspective: Improving vitamin D status in the management of Covid-19. Eur J Clin Nutr 74(6): 856-859.

26. Liu PT, Stenger S, Li H, Wenzel L, Tan BH, et al. (2006) Toll-like receptor triggering of a vitamin D-mediated human antimicrobial response. Science 311(5768): 1770-1773.

27. Adams JS, Ren S, Liu PT, Chun RF, Lagishetty V, et al. (2009) Vitamin D-directed rheostatic regulation of monocyte antibacterial responses. J Immunol 182(7): 4289-4295.

28. Herr C, Shaykhiev R, Bals R (2007) The role of cathelicidin and defensins in pulmonary inflammatory diseases. Expert Opin Biol Ther 7(9): 14491461.

29. Barlow PG, Svoboda P, Mackellar A, Nash AA, York IA, et al. (2011) Antiviral activity and increased host defense against influenza infection elicited by the human cathelicidin LL-37. PLoS One 6(10).

30. Liu PT, Stenger S, Tang DH, Modlin RL (2007) Cutting edge: Vitamin D-mediated human antimicrobial activity against mycobacterium tuberculosis is dependent on the induction of cathelicidin. J Immunol 179(4): 2060-2063.

31. Brighenti S, Bergman P, Martineau AR (2018) Vitamin D and tuberculosis: Where next? J Intern Med 284(2): 145-162.

32. Martínez Moreno J, Hernandez JC, Urcuqui Inchima S (2020) Effect of high doses of vitamin D supplementation on dengue virus replication, toll-like receptor expression, and cytokine profiles on dendritic cells. Mol Cell Biochem 464(1-2): 169-180.

33. Sharifi A, Vahedi H, Nedjat S, Rafiei H, Hosseinzadeh Attar MJ (2019) Effect of single-dose injection of vitamin D on immune cytokines in ulcerative colitis patients: A randomized placebo-controlled trial. Apmis 127(10): 681-687. 
34. Hoffmann M, Kleine Weber H, Schroeder S, Krüger N, Herrler T, et al (2020) SARS-CoV-2 cell entry depends on ACE2 and TMPRSS2 and is blocked by a clinically proven protease inhibitor. Cell 181(2): 271-280. e8.

35. Xu J, Yang J, Chen J, Luo Q Zhang Q (2017) Vitamin D alleviates lipopolysaccharide-induced acute lung injury via regulation of the reninangiotensin system. Mol Med Rep 16(5): 7432-7438.

36. Phokela SS, Peleg S, Moya FR, Alcorn JL (2005) Regulation of human pulmonary surfactant protein gene expression by $1 \alpha, 25$ dihydroxyvitamin D3. Am J Physiol Lung Cell Mol Physiol 289(433-434): 617-626.

37. Bombardini T, Picano E (2020) Angiotensin-converting enzyme 2 as the molecular bridge between epidemiologic and clinical features of Covid-19. Can J Cardiol 36(5): 784

38. Rehan VK, Torday JS, Peleg S, Gennaro L, Vouros P, et al. (2020) 1 $\alpha, 25$ Dihydroxy-3-epi-vitamin D3, a natural metabolite of $1 \alpha, 25$-dihydroxy vitamin D3: Production and biological activity studies in pulmonary alveolar type II cells. Mol Genet Metab 76(1): 46-56.

39. Hastie CE, Mackay DF, Ho F, Celis Morales CA, Katikireddi SV, et al. (2020) Vitamin D concentrations and Covid-19 infection in UK Biobank. Diabetes Metab Syndr Clin Res Rev 14(4): 561-565.

40. Chang SW, Lee HC (2019) Vitamin D and health: The missing vitamin in humans. Pediatr Neonatol 60(3): 237-244

41. Michelson JD, Charlson MD (2016) Vitamin D status in an elective orthopedic surgical population. Foot Ankle Int 37(2): 186-191.

42. Marcelli C, Chavoix C, Dargent Molina P (2014) Beneficial effects of vitamin $\mathrm{D}$ on falls and fractures: Is cognition rather than bone or muscle behind these benefits? Osteoporos Int 26(1): 1-10.

43. Tutaworn T, Phruetthiphat O, Songpatanasilp T (2019) Prevalence and clinical correlation of vitamin D inadequacy in traumatic hip fracture among elderly patients. Journal of Orthopedics \& Bone Disorders: 1-8.

44. Moran CG, Wenn RT, Sikand M, Taylor AM (2005) Early mortality after hip fracture: Is delay before surgery important? J Bone Jt Surg - Ser A 87(3): 483-489.

45. Kahwati LC, Weber RP, Pan H, Gourlay M, Le Blanc E, et al. (2018) Vitamin $\mathrm{D}$, calcium, or combined supplementation for the primary prevention of fractures in community-dwelling adults evidence report and systematic review for the US Preventive Services Task Force. JAMA - J Am Med Assoc 319(15): 1600-1612.

46. Gorter EA, Krijnen P, Schipper IB (2017) Vitamin D status and adult fracture healing. J Clin Orthop Trauma [Internet] 8(1): 34-37.

47. Conradie M, Ascott Evans B (2013) An interesting D-lemma: What is all the excitement about vitamin D? South African Fam Pract 55(2): $157-$ 160.

48. Grammatiki M, Rapti E, Karras S, Ajjan RA, Kotsa K (2017) Vitamin D and diabetes mellitus: Causal or casual association? Rev Endocr Metab Disord 18(2): 227-241.

49. Aljabri KS, Alnasser IM, Bokhari SA, Alshareef MA, Khan PM, et al. (2019) Vitamin D deficiency in elderly Saudi patients with type 2 diabetes mellitus. Int J Endocrinol 15(6): 459-468.

50. Kumar V, Patel BY, Robinson AH (2019) Diabetes and orthopaedic surgery: A review. Orthop Trauma 33(4): 212-216.

51. Wukich DK (2015) Diabetes and its negative impact on outcomes in orthopaedic surgery. World J Orthop 6(3): 331-339.

52. Plotnikoff GA, Quigley JM (2003) Prevalence of severe hypovitaminosis D in patients with persistent, nonspecific musculoskeletal pain. Mayo Clin Proc 78(12): 1463-1470.

53. Christodoulou S, Goula T, Ververidis A, Drosos G, GD (2013) Vitamin D and bone disease. Biomed Res Int 2013: 1-6.

54. Gharaibeh A, Kupershtein M, Gharaibeh M, Filip V, Sokol D, et al. (2020)
Relation between vitamin D deficiency and osteoarthritis. J Orthop Bone Disord 5(1): 1-4.

55. Cakar M, Ayanoglu S, Cabuk H, Seyran M, Dedeoglu SS, et al. (2018) Association between vitamin $\mathrm{D}$ concentrations and knee pain in patients with osteoarthritis. PeerJ 2018(4): 1-9.

56. Geraci A, Tomasello G, Sabetta SP (2010) Orthopaedic experience on inflammatory bowel disease (Lesniowski-Crohn's disease and ulcerative colitis). Ortop Traumatol Rehabil 12(5): 430-434.

57. Narula N, Marshall JK (2012) Management of inflammatory bowel disease with vitamin D: Beyond bone health. J Crohn's Colitis 6(4): 397404.

58. Weldon D (2009) The effects of corticosteroids on bone: Osteonecrosis (avascular necrosis of the bone). Ann Allergy, Asthma Immunol 103(2): 91-98.

59. Fletcher J, Cooper SC, Ghosh S, Hewison M (2019) The role of vitamin D in inflammatory bowel disease: Mechanism to management. Nutrients 11(5): 1019.

60. Nielsen OH, Hansen TI, Gubatan JM, Jensen KB, Rejnmark L (2019) Managing vitamin D deficiency in inflammatory bowel disease. Frontline Gastroenterol 10(4): 394-400.

61. Aslam MM, John P, Bhatti A, Jahangir S, Kamboh MI (2019) Vitamin D as a principal factor in mediating rheumatoid arthritis-derived immune response. Biomed Res Int 2019: 1-12.

62. Bragazzi NL, Watad A, Neumann SG, Simon M, Brown SB, et al. (2017) Vitamin D and rheumatoid arthritis: An ongoing mystery. Curr Opin Rheumatol 29(4): 378-388.

63. Cutolo M, Otsa K, Uprus M, Paolino S, Seriolo B (2007) Vitamin D in rheumatoid arthritis. Autoimmun Rev 7(1): 59-64.

64. Welsh P, Peters MJL, Sattar N (2011) Is vitamin D in rheumatoid arthritis a magic bullet or a mirage? The need to improve the evidence base prior to calls for supplementation. Arthritis Rheum 63(7): 1763-1769.

65. Snyders R, Jordaan J, Rasool M, Goga I (2016) Vitamin D status in patients undergoing arthroplasty. SA Orthop J 15(4): 43-46.

66. Workineh M, Mathewos B, Moges B, Gize A, Getie S, et al. (2017) Vitamin D deficiency among newly diagnosed tuberculosis patients and their household contacts: A comparative cross-sectional study. Arch Public Heal 75(1): 1-7.

67. Junaid K, Rehman A (2019) Impact of vitamin D on infectious diseasetuberculosis: A review. Clin Nutr Exp 25: 1-10.

68. Wu H, Xiong X, Zhu M, Wei J, Zhuo K, et al. (2018) Effects of vitamin D supplementation on the outcomes of patients with pulmonary tuberculosis: A systematic review and meta-analysis. BMC Pulm Med 18(1): 1-12

69. Talat N, Perry S, Parsonnet J, Dawood G, Hussain R (2010) Vitamin D deficiency and tuberculosis progression. Emerg Infect Dis 16(5): 853855 .

70. Agarwal A, Mishra M, Dabla PK, Sharma S (2015) Vitamin D status in pediatric osteoarticular tuberculosis. J Clin Orthop Trauma 6(4): 227229.

71. Soeharto DA, Rifai DA, Marsudidjadja S, Roekman AE, Assegaf CK, et al. (2019) Vitamin D as an adjunctive treatment to standard drugs in pulmonary tuberculosis patients: An evidence-based case report. Adv Prev Med 2019: 1-10.

72. Lee SU, Na KT, Lee YM, Park JH, Joo SY (2020) Low vitamin D levels in post-menopausal women are associated with complex regional pain syndrome type I in surgically treated distal radius fractures. J Orthop Surg Res 15(1): 2-7.

73. Aïm F, Klouche S, Frison A, Bauer T, Hardy P (2017) Efficacy of vitamin $\mathrm{C}$ in preventing complex regional pain syndrome after wrist fracture: 
A systematic review and meta-analysis. Orthop Traumatol Surg Res 103(3): 465-470.

74. Ameri R Al (2020) Vitamin D deficiency among depressed women. J Qual Heal Care Econ 3(1): 1-8.

75. Farrington E, Moller M (2013) Relationship of vitamin d3 deficiency to depression in older adults: A systematic review of the literature from 2008-2013. J Nurse Pract 9(8): 506-515.

76. Okereke OI, Reynolds CF, Mischoulon D, Chang G, Vyas CM, et al. (2020) Effect of long-term vitamin d3 supplementation vs placebo on risk of depression or clinically relevant depressive symptoms and on change in mood scores: A randomized clinical trial. Jama 324(5): 471-480.

77. Alavi NM, Khademalhoseini S, Vakili Z, Assarian F (2019) Effect of vitamin D supplementation on depression in elderly patients: A randomized clinical trial. Clin Nutr 38(5): 2065-2070.

78. Anglin RES, Samaan Z, Walter SD, Sarah DM (2013) Vitamin D deficiency and depression in adults: Systematic review and meta-analysis. $\mathrm{Br}$ Psychiatry 202(2): 100-107.

79. Penckofer S, Byrn M, Adams W, Emanuele MA, Mumby P, et al. (2017) Vitamin D supplementation improves mood in women with type 2 diabetes. J Diabetes Res 2017 : 8232863.

80. Libuda L, Laabs BH, Ludwig C, Bühlmeier J, Antel J, et al. (2019) Vitamin
ISSN: 2574-1241

DOI: $10.26717 /$ BJSTR.2020.30.005021

Makgabo John Tladi. Biomed J Sci \& Tech Res

(C) $(9)$ This work is licensed under Creative

Submission Link: https://biomedres.us/submit-manuscript.php
D and the risk of depression: A causal relationship? Findings from a Mendelian randomization study. Nutrients 11(5) :1085.

81. Kumar S, Verma V, Kushwaha U, Calvello Hynes EJ, Arya A, et al. (2020) Prevalence and association of depression in in-patient orthopaedic trauma patients: A single centre study in India. J Clin Orthop Trauma 11(5): 573-S577.

82. La A, Nadarajah V, Jauregui JJ, Shield WP, Medina SH, et al. (2020) Clinical characteristics associated with depression or anxiety among patients presenting for knee surgery. J Clin Orthop Trauma 11(1): 164-170.

83. Obayemi JE, Card EB, Shirima O, Massawe H, Mandari F, et al. (2019) Psychosocial health of patients receiving orthopaedic treatment in northern Tanzania: A cross-sectional study. Ann Med Surg 50: 49-55.

84. Pepper KJ, Judd SE, Nanes MS, Tangpricha V (2009) Evaluation of vitamin D repletion regimens to correct vitamin D status in adults. Endocr Pract 15(2): 95-103.

85. Clifford J, Rosen (2011) Vitamin D insufficiency. N Engl J Med 364: 248254.

86. Tladi J (2018) Do we need to investigate for vitamin D levels in patients going for correction? Foot Ankle Stud 2(2): 1018.

$\begin{array}{ll}\text { BIOMEDICAL } & \text { Assets of Publishing with us } \\ \text { RESEARCHES } & \text { - Global archiving of articles } \\ & \text { - Immediate, unrestricted online access } \\ & \text { - Rigorous Peer Review Process } \\ & \end{array}$

